BMJ

Open

Gastroenterology

\section{Quality of life in patients with IBD during the COVID-19 pandemic in the Netherlands}

To cite: de Bock E, Filipe MD, Meij V, et al. Quality of life in patients with IBD during the COVID-19 pandemic in the Netherlands. BMJ Open Gastro 2021;8:e000670. doi:10.1136/ bmjgast-2021-000670

Received 2 April 2021 Accepted 7 June 2021
Check for updates

(c) Author(s) (or their employer(s)) 2021. Re-use permitted under CC BY-NC. No commercial re-use. See rights and permissions. Published by BMJ.

${ }^{1}$ Surgery, UMC Utrecht, Utrecht, The Netherlands

${ }^{2}$ Gastroenterology and Hepatology, UMC Utrecht, Utrecht, The Netherlands ${ }^{3}$ Internal Medicine, Section Pharmacotherapy, Amsterdam UMC, Locatie VUmc, Amsterdam, The Netherlands

Correspondence to Dr Milan C Richir; m.richir@vumc.n

\section{ABSTRACT}

Objective COVID-19 has put a strain on regular healthcare worldwide. For inflammatory bowel disease (IBD), gastrointestinal surgeries were postponed and changes in treatment and diagnostic procedures were made. As abrupt changes in treatment regimens may result in an increased morbidity and consequent wellbeing of patients with IBD, the aim of this study was to determine the effect of the COVID-19 pandemic on healthrelated quality of life (HRQoL) in patients with IBD.

Design All patients with IBD who completed both Inflammatory Bowel Disease Questionnaire (IBDQ) and 36-Item Short Form Health Survey (SF-36) questionnaire between 31 August and 13 September 2020 were included in our cohort study. The primary end point was to determine the $\mathrm{HRQOL}$ in patients with IBD, measured by the IBDQ and SF-36 questionnaire. The secondary end point was determining which factors influence the $\mathrm{HRQOL}$ in patients with IBD.

Results 582 patients with IBD filled in the IBDQ and SF-36 questionnaire. The HRQoL in our study population was low according to the questionnaires on both physical and mental subscales. In addition, multivariate analysis showed that increased age, female sex and patients who underwent surgery had a significantly lower HRQoL, most frequently on the physical domains in both questionnaires. Conclusion Patients with IBD had an overall low HRQoL during the COVID-19 pandemic. Furthermore, older patients, women and patients who underwent surgical procedures had the lowest physical HRQoL.

\section{INTRODUCTION}

The first wave of the COVID-19 pandemic has led to an increase in patients with COVID-19 requiring hospital healthcare. This influx called for measures to limit the impact of the virus on the healthcare system by prioritising care. As a consequence, only (semi)acute procedures, typically those involving oncological, acute gastrointestinal, vascular and trauma surgery, were able to be continued. ${ }^{1-3}$ This meant that many types of elective surgical procedures, including gastrointestinal surgery due to inflammatory bowel disease (IBD), were postponed. In addition,

\section{Summary box}

What is already known about this subject?

- During the COVID-19 pandemic, healthcare measures were taken to facilitate intensive care unit capacity and reduce the risk of viral spreading. Inflammatory bowel disease (IBD) care was postponed or altered due to a lower healthcare priority. IBD care is partially based on the patients' clinical symptom experience. Postponement of IBD care may result in more disease activity and thereby in further clinical deterioration, which may be observed in quality of life (QoL) scores.

- The influence of the pandemic on IBD care is limited. There are no prior studies that have quantified physical and emotional scores by using validated questionnaires among patients with IBD during the pandemic.

What are the new findings?

- The health-related QoL (HRQoL) in the study population was low according to the Inflammatory Bowel Disease Questionnaire and the 36-Item Short Form Health Survey questionnaire on both physical and mental subscales.

- In addition, multivariate analysis showed that increased age, female sex and patients who underwent surgery had a significantly lower $\mathrm{HRQ}$ oL, most frequently on the physical domains in both questionnaires. Furthermore, higher scores on the emotional health domains were seen in older patients with IBD compared with younger patients.

How might it impact on clinical practice in the foreseeable future?

- This study shows that in the event of a new wave or similar pandemics, caution in postponing IBD care is essential to prevent a decrease in the HRQoL of patients with IBD.

- Furthermore, our study provides additional information for future studies that may determine for which patients with IBD a delay of treatment is feasible and for which patients a delay of IBD care could lead to increased morbidity. This is essential in contributing to provide care resulting in the most optimal well-being of patients with IBD . 
changes in medical treatment and diagnostic procedures for patients with IBD were made. ${ }^{4-10}$ Therefore, non-urgent care, including treatment of patients with IBD, has a lower healthcare priority. Furthermore, basic measures were taken in the Netherlands to reduce the spread of COVID-19, including the advice to stay at home if possible and to limit the number of social contacts. ${ }^{11}$

IBD is a chronic and multifactorial disease comprising ulcerative colitis (UC) and Crohn's disease (CD) and has an increasing prevalence around the world. ${ }^{12}$ Treatment of IBD symptoms as a result of inflammatory activity consists of immunosuppressive medication, combined with a possible surgical procedure. ${ }^{13}$ Most patients requiring surgery are facing inadequate control of IBD-specific symptoms, experiencing intolerable side effects or presenting with complications of the disease such as intestinal bowel obstruction, fistula, perforations or stenosis. ${ }^{13-15}$ Symptom monitoring remains one of the key components of the disease course in patients with IBD. ${ }^{1316}$ Therefore, to objectify the disease course in patients with IBD, their health-related quality of life (HRQoL) is measured. Treatment of patients with IBD requires a complex and multidisciplinary approach, and abrupt changes in treatment regimens and options may result in an increased morbidity and consequent wellbeing of patients with IBD. Therefore, the aim of this study is to determine the HRQoL during the COVID-19 pandemic in patients with IBD in the Netherlands.

\section{MATERIALS AND METHODS}

\section{Study design and patient selection}

This study consisted of a self-administered single-point survey, in which details on demographics, IBD medication and the physical and emotional impact of the COVID-19 lockdown period were collected. The survey was distributed electronically to all panel members registered in the national database of the Dutch Crohn's and Colitis Association. This panel consisted of patients with IBD who would like to be involved in IBD healthcare and research. The panel was composed of patients from as many different regions and age groups as possible to obtain a representative view of the IBD population in the Netherlands and currently consists of 1932 patients. ${ }^{17}$ Participants were included if they were older than 18 years and filled in both the Inflammatory Bowel Disease Questionnaire (IBDQ) and 36-Item Short Form Health Survey (SF-36) questionnaire between 31 August and 13 September 2020. Patients were excluded when the final diagnosis was not yet determined or when they were diagnosed with proctitis, as proctitis can have other causes besides CD and UC.

\section{HRQoL assessment}

36-Item Short Form Health Survey

SF-36 is a non-disease-specific questionnaire to assess all the domains for a general health condition, containing 36 items. This questionnaire is further categorised into eight groups: physical functioning, role limitations due to physical health problems, bodily pain, general health perception, vitality, social functioning, role limitations due to emotional problems and mental health. In addition, the physical component scale (PCS) is the sum of physical functioning, role limitations due to physical problems, bodily pain and general health domains, and the mental component scale (MCS) is the sum of vitality, social functioning, role limitations due to emotional problems and mental health domains. Social functioning scores range from 0 to 100 , with a higher score indicating a better health condition. ${ }^{18} 19$

\section{Inflammatory Bowel Disease Questionnaire}

The IBDQ is a disease-specific QoL questionnaire. It consists of 32 items, which are divided into four domains: bowel-related symptoms, systematic symptoms, emotional function and social function. Responses are graded on a seven-point scale in which 1 indicates the worst function and 7 the best function. The total IBDQ score gives a possible range of 32-224, with a higher score indicating a better QoL. ${ }^{20} 21$

\section{End points and definitions}

The primary end point was to ascertain the patientreported outcome measured using the IBDQ and SF-36 questionnaire. The secondary end point was determining the effect of age, gender, type of IBD and operation performed on different domains of the HRQoL.

Patients were stratified according to the type of IBD, including CD and UC. Patients who underwent a previous surgical procedure, during or before the COVID-19 pandemic, were stratified by the number of surgical procedures performed. Patients who underwent a previous surgical procedure were stratified into five categories as well: previous $0-5$ years, previous $6-10$ years, previous 11-15 years, previous 16-20 years and longer than 20 years. Types of medical treatment included, but were not limited to, biologicals (eg, infliximab, adalimumab, golimumab, vedolizumab, ustekinumab and tofacitinib), corticosteroids (eg, prednis(ol)one, budesonide, betamethasone and beclomethasone), immunosuppressants (eg, azathioprine, ciclosporin, mercaptopurine, methotrexate and thioguanine), mesalamines (eg, sulfasalazine and mesalazine), supportive medication (eg, loperamide and cholestyramine) and research medication.

\section{Statistical analysis}

Descriptive statistics were used to describe the patient and treatment characteristics. Continuous data are reported as mean and standard deviation (SD).

Multivariate linear regression was used to determine which factors determine QoL in the different domains of both HRQoL questionnaires. $\mathrm{P}$ values below 0.05 were considered significant.

All calculations were performed using RStudio V.1.2.5001 (with R V.×64 3.6.3). 


\section{RESULTS}

\section{Baseline characteristics}

Between 31 August and 13 September 2020, 582 (30.6\%) patients with IBD completed both questionnaires. Of these patients, $179(32.8 \%)$ were men. The mean age of the study population was 52.8 years $(\mathrm{SD}=14.9$, range $=13-85$ years), and the mean age of IBD diagnosis was 35 years. The diagnosis of $\mathrm{CD}$ was the most frequent type of IBD in $327(56.2 \%)$ patients and UC in $255(43.8 \%)$ patients. In $193(35.0 \%)$ patients, a surgical intervention for IBD was performed. Most of these patients $(80.8 \%)$ were diagnosed with CD compared with $19.2 \%$ with UC. The mean time between the year of IBD diagnosis and first surgery was 7 years. The majority of the surgical patients $(33.7 \%)$ were operated once. Of the 193 surgical patients, 37 $(19.2 \%)$ required more than five surgical procedures. In total, $480(82.5 \%)$ patients received medical therapy at the time of questionnaire (table 1).

\section{QoL using SF-36 and IBDQ}

Figure 1 presents the general health of the patients with IBD using the mean scores of the SF-36 questionnaire. The mean scores on the PCS and MCS were 36.3 and 50.8 , respectively. The highest mean score was observed for the mental health domain (mean score $=73.2$ ) and the lowest score for the physical functioning domain (mean score $=45.3$ ). Furthermore, figure $2 \mathrm{~A}, \mathrm{~B}$ displays the disease-specific health status of the participants using the mean scores of the IBDQ. The total IBDQ score in our study population is 171.3 ( $\mathrm{SD}=31.04)$. The mean scores on the physical components of the IBDQ were 54.4 and 22.8 for bowel symptoms and systemic symptoms, respectively. Emotional function and social function contributed to the mental domains of the IBDQ with mean scores of 65.5 and 28.6, respectively.

\section{Factors associated with $\mathrm{HRQOL}$}

Multivariate analysis of the SF-36 questionnaire showed that higher age was a significant predictor of lower score on physical functioning $(\mathrm{p}<0.001)$ and PCS $(\mathrm{p}=0.006)$ and of higher score on vitality $(\mathrm{p}=0.041)$ and MCS $(p=0.005)$. Furthermore, female gender was a significant contributor to a lower median score of the SF-36 for physical functioning $(p=0.013)$, role limitations due to physical health problems $(\mathrm{p}=0.028)$, bodily pain $(\mathrm{p}=0.007)$, social functioning $(\mathrm{p}=0.017)$ domains and the PCS $(p=0.003)$. Finally, a history of surgical IBD procedure was a significant predictor of a lower median score on the role limitations due to physical health problems domain $(p=0.026)$ and PCS $(p=0.08)$. Type of IBD was not a significant contributor to the HRQoL domains of the SF-36 (table 2).

Multivariate analysis of the IBDQ showed that a history of IBD surgery performed was a significant predictor of a lower score in bowel symptoms, systemic symptoms, social function and the total IBDQ scores, with $\mathrm{p}$ values of $0.033,0.049,<0.001$ and 0.014 , respectively. Furthermore, higher age $(\mathrm{p}=0.003)$ was a significant predictor

\begin{tabular}{|c|c|}
\hline Parameter & Value \\
\hline Age, years, mean (SD) & $52.83(14.9)$ \\
\hline Sex, male, n (\%) & $179(32.8)$ \\
\hline Age at diagnosis of IBD, years, mean (SD) & $35(17.6)$ \\
\hline \multicolumn{2}{|l|}{ Type of IBD } \\
\hline Crohn's disease, n (\%) & $327(56.2)$ \\
\hline Ulcerative colitis, n (\%) & $255(43.8)$ \\
\hline Operated & $193(35.0)$ \\
\hline Crohn’s disease, n (\%) & $156(80.8)$ \\
\hline Ulcerative colitis, n (\%) & $37(19.2)$ \\
\hline $\begin{array}{l}\text { Time between IBD diagnosis and first } \\
\text { surgery, years, mean (SD) }\end{array}$ & 7 (14.5) \\
\hline Surgery $1, \mathrm{n}(\%)$ & $65(33.7)$ \\
\hline Surgery $2, \mathrm{n}(\%)$ & $41(21.2)$ \\
\hline Surgery $3, \mathrm{n}(\%)$ & $31(16.1)$ \\
\hline Surgery $4, \mathrm{n}(\%)$ & $13(6.7)$ \\
\hline Surgery $5, \mathrm{n}(\%)$ & $6(3.1)$ \\
\hline Surgery >5, n (\%) & $37(19.2)$ \\
\hline \multicolumn{2}{|l|}{ First surgery } \\
\hline Previous 0-5 years, n (\%) & $30(16.4)$ \\
\hline Previous 6-10 years, $\mathrm{n}(\%)$ & $30(16.3)$ \\
\hline Previous $11-15$ years, $\mathrm{n}(\%)$ & $25(13.6)$ \\
\hline Previous $16-20$ years, $n(\%)$ & $22(15.3)$ \\
\hline Longer than 20 years, $\mathrm{n}(\%)$ & $69(37.9)$ \\
\hline Medication for IBD, n (\%) & $480(82.5)$ \\
\hline Biologicals, n (\%) & $217(37.3)$ \\
\hline Corticosteroids, n (\%) & $63(10.8)$ \\
\hline Immunosuppressants, n (\%) & $171(29.4)$ \\
\hline Mesalamines, $\mathrm{n}(\%)$ & $183(31.4)$ \\
\hline Research, n (\%) & $7(1.2)$ \\
\hline Supportive, n (\%) & $51(8.8)$ \\
\hline Other, n (\%) & 65 (11.2) \\
\hline
\end{tabular}

IBD, inflammatory bowel disease.;

of scoring higher on the emotional function domain. In addition, in scoring on systemic symptoms, female gender $(p=0.001)$ was a significant predictor to result in a lower mean score. Type of IBD was not a significant contributor to the HRQoL domains of the IBDQ (table 3).

\section{DISCUSSION}

This study analysed 582 patients with IBD who completed the SF-36 and IBD-specific questionnaires during the COVID-19 pandemic. The overall HRQoL in our IBD participants during the pandemic is low. Furthermore, older patients, women and patients who have undergone surgery have a significant lower physical HRQoL.

During the pandemic, healthcare measures in different disciplines were taken to facilitate the intensive care 


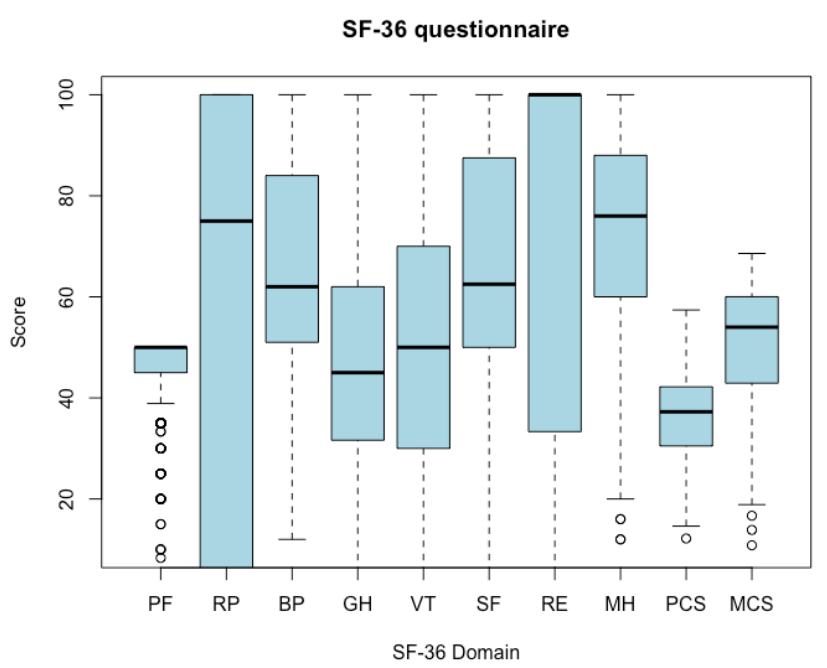

Figure 1 Boxplot of the subscales of the 36-Item Short Form Health Survey including BP, bodily pain; GH, general health; PCS, physical component scale; PF, physical function; MCS, mental component scale; $\mathrm{MH}$, mental health; $\mathrm{RE}$, role limitations due to emotional health problems; RP, role limitations due to physical health problems; SF, social function; SF-36, 36-Item Short Form Health Survey; VT, vitality.

capacity for patients with COVID-19, while at the same time non-COVID-19 care was minimalised to reduce the pressure on healthcare. ${ }^{1-10}$ A recent study describes a decrease in IBD care performed as a result of the pandemic. $^{22}$ Due to changes in the healthcare priority, the HRQoL of the patients with IBD may have decreased. This study describes the HRQoL of patients with IBD during the COVID-19 pandemic.

This study showed an overall low HRQoL, based on the SF-36 questionnaire, in our study population. The SF-36 questionnaire showed that our study population had lower scores compared with a recent study during the COVID-19 pandemic with non-chronically ill patients, indicating an inferior general health in our patients with IBD during the lockdown. ${ }^{23}$ Furthermore, HRQoL measured by the SF-36 questionnaire showed that patients with IBD experienced a lower physical HRQoL during the pandemic compared with Dutch patients with IBD outside the pandemic as shown in earlier prepandemic studies (mean PCS=45.7-63). ${ }^{24-26}$ This may be explained by the healthcare changes needed during the pandemic, including reduced performance of diagnostic endoscopy, reduced access to outpatient clinic visits and postponement of surgical procedures. ${ }^{7827}$ Due to this postponement of regular care and altered medical treatment, patients with IBD may have a higher risk of physical adverse outcomes. ${ }^{28}$ Therefore, the low HRQoL score, focused on the general health, in our patients with IBD may be explained by these possible consequences of the healthcare postponement as a result of the pandemic.

This study displays that our Dutch patients with IBD score low on the IBDQ, the disease-specific questionnaire for
IBD Questionnaire (IBDQ)
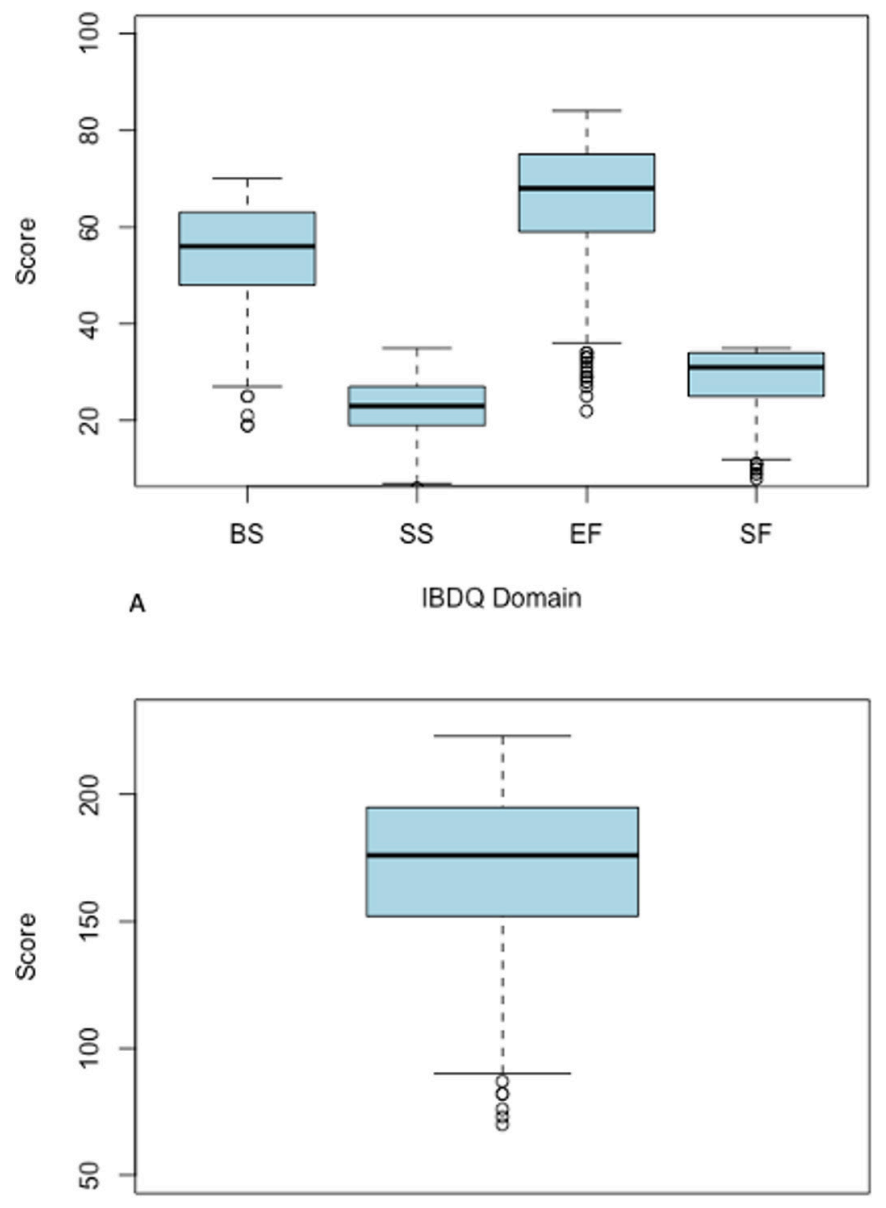

B

IBDQ total

Figure 2 A) Boxplot of the subscales of the Inflammatory Bowel Disease Questionnaire (IBDQ) including BS, bowel symptoms; SS, systemic symptoms; EF, emotional function; SF, social function and B) IBDQ Total score.

IBD, indicating an overall low HRQoL. These scores were lower compared with prepandemic studies in the Dutch IBD population (mean total IBDQ score $=173-181$, mean bowel symptoms $=53-57$, mean systemic symptoms $=24-26$, mean emotional function $=65-68$ and mean social function=29-30). ${ }^{24} 2529$ The changed measures during the pandemic, described previously, come with uncertainty and stress, which could explain the low score of the emotional function and social function domains of the IBDQ in our study population. ${ }^{30-32}$ Optimal IBD course consists of clinical symptoms combined with monitoring of biomarkers such as faecal calprotectin and $\mathrm{C}$ reactive protein. ${ }^{13} 3334$ However, during the pandemic, outpatient clinic visits were cancelled, resulting in reduced ability to collect blood for possible follow-up of biomarkers. Our data regarding the bowel function and systemic symptoms subscales of the IBDQ and PCS of the SF-36 illustrated worsening of intestinal problems during the pandemic compared with previously mentioned Dutch prepandemic studies. ${ }^{24-2629}$ As IBD 
Table 2 Multivariate analysis of predictors determining different outcomes of the domains from the SF-36 questionnaire

\begin{tabular}{|c|c|c|c|c|}
\hline Parameter & Estimate & SE & $z$ value & $P$ value \\
\hline \multicolumn{5}{|l|}{ PF } \\
\hline Age & -0.143 & 0.023 & -6.154 & $<0.001$ \\
\hline Sex & -1.844 & 0.736 & -2.507 & 0.013 \\
\hline CD & 0.252 & 0.743 & 0.339 & 0.735 \\
\hline Surgery & -1.354 & 0.769 & -1.761 & 0.079 \\
\hline \multicolumn{5}{|l|}{$\mathrm{RP}$} \\
\hline Age & -0.064 & 0.128 & -0.500 & 0.617 \\
\hline Sex & -8.924 & 4.036 & -2.211 & 0.028 \\
\hline$C D$ & 0.531 & 4.062 & 0.131 & 0.896 \\
\hline Surgery & -9.4 & 4.208 & -2.234 & 0.026 \\
\hline \multicolumn{5}{|l|}{$\mathrm{BP}$} \\
\hline Age & -0.104 & 0.067 & -1.555 & 0.120 \\
\hline Sex & -5.788 & 2.125 & -2.723 & 0.007 \\
\hline CD & 1.974 & 2.145 & 0.92 & 0.358 \\
\hline Surgery & -4.25 & 2.221 & -1.913 & 0.056 \\
\hline \multicolumn{5}{|l|}{$\mathrm{GH}$} \\
\hline Age & -0.005 & 0.059 & -0.079 & 0.937 \\
\hline Sex & -0.377 & 1.889 & -0.200 & 0.842 \\
\hline$C D$ & 0.932 & 1.909 & 0.488 & 0.625 \\
\hline Surgery & -3.261 & 1.977 & -1.650 & 0.100 \\
\hline \multicolumn{5}{|l|}{ VT } \\
\hline Age & 0.141 & 0.069 & 2.048 & 0.041 \\
\hline Sex & -3.843 & 2.187 & -1.757 & 0.080 \\
\hline$C D$ & 3.45 & 2.208 & 1.562 & 0.119 \\
\hline Surgery & -1.78 & 2.286 & -0.779 & 0.437 \\
\hline \multicolumn{5}{|l|}{ SF } \\
\hline Age & -0.066 & 0.072 & -0.924 & 0.356 \\
\hline Sex & -5.496 & 2.284 & -2.406 & 0.017 \\
\hline$C D$ & 0.221 & 2.308 & 0.096 & 0.924 \\
\hline Surgery & -4.3 & 2.39 & -1.799 & 0.073 \\
\hline \multicolumn{5}{|l|}{$\mathrm{RE}$} \\
\hline Age & 0.165 & 0.118 & 1.398 & 0.163 \\
\hline Sex & 0.717 & 3.734 & 0.192 & 0.848 \\
\hline$C D$ & -4.944 & 3.764 & -1.314 & 0.19 \\
\hline Surgery & -2.888 & 3.899 & -0.741 & 0.459 \\
\hline \multicolumn{5}{|l|}{$\mathrm{MH}$} \\
\hline Age & 0.101 & 0.055 & 1.831 & 0.068 \\
\hline Sex & 0.273 & 1.744 & 0.156 & 0.876 \\
\hline$C D$ & -0.727 & 1.761 & -0.413 & 0.680 \\
\hline Surgery & -1.315 & 1.823 & -0.722 & 0.471 \\
\hline \multicolumn{5}{|l|}{ PCS } \\
\hline Age & -0.067 & 0.024 & -2.773 & 0.006 \\
\hline Sex & -2.233 & 0.758 & -2.947 & 0.003 \\
\hline$C D$ & 0.713 & 0.771 & 0.925 & 0.356 \\
\hline Surgery & -2.116 & 0.790 & -2.677 & 0.008 \\
\hline
\end{tabular}

Continued
Table 2 Continued

\begin{tabular}{lllll} 
Parameter & Estimate & SE & z value & P value \\
\hline MCS & & & & \\
Age & 0.096 & 0.0344 & 2.804 & 0.005 \\
Sex & 0.030 & 1.078 & 0.028 & 0.978 \\
CD & -0.671 & 1.097 & -0.612 & 0.541 \\
Surgery & -0.725 & 1.124 & -0.645 & 0.519
\end{tabular}

BP, bodily pain; CD, Crohn's disease; GH, general health; IBD, inflammatory bowel disease; MCS, mental component scale; $\mathrm{MH}$, mental health; PCS, physical component scale; PF, physical function; RE, role limitations due to emotional health problems; RP, role limitations due to physical health problems; SF- 36, 36-Item Short Form Mental Health Survey; SF, social function; VT, vitality.

care is partially based on the patients' clinical symptom experience, postponement of IBD care may result in more disease activity and thereby in further clinical deterioration. ${ }^{131635-37}$ This may lead to additional care, which

Table 3 Multivariate analysis of predictors determining different outcomes of the domains from the IBDQ

\begin{tabular}{|c|c|c|c|c|}
\hline Parameter & Estimate & SE & $z$ value & $P$ value \\
\hline \multicolumn{5}{|l|}{ BS } \\
\hline Age & 0.035 & 0.03 & 1.166 & 0.244 \\
\hline Sex & -1.779 & 0.954 & -1.865 & 0.063 \\
\hline CD & 1.211 & 0.976 & 1.241 & 0.215 \\
\hline Surgery & -2.14 & 1.002 & -2.137 & 0.033 \\
\hline \multicolumn{5}{|l|}{ SS } \\
\hline Age & 0.031 & 0.018 & 1.786 & 0.075 \\
\hline Sex & -1.814 & 0.561 & -3.235 & 0.001 \\
\hline$C D$ & 0.186 & 0.572 & 0.326 & 0.745 \\
\hline Surgery & -1.159 & 0.587 & -1.975 & 0.049 \\
\hline \multicolumn{5}{|l|}{ EF } \\
\hline Age & 0.105 & 0.035 & 2.993 & 0.003 \\
\hline Sex & 0.079 & 1.108 & 0.071 & 0.943 \\
\hline$C D$ & -0.371 & 1.13 & -0.328 & 0.743 \\
\hline Surgery & -2.181 & 1.153 & -1.892 & 0.059 \\
\hline \multicolumn{5}{|l|}{ SF } \\
\hline Age & 0.001 & 0.019 & 0.070 & 0.944 \\
\hline Sex & -0.812 & 0.594 & -1.366 & 0.173 \\
\hline CD & 0.337 & 0.605 & 0.557 & 0.578 \\
\hline Surgery & -2.475 & 0.622 & -3.981 & $<0.001$ \\
\hline \multicolumn{5}{|l|}{ IBDQ total } \\
\hline Age & 0.178 & 0.091 & 1.949 & 0.052 \\
\hline Sex & -3.854 & 2.865 & -1.345 & 0.179 \\
\hline CD & 1.631 & 2.928 & 0.557 & 0.578 \\
\hline Surgery & -7.408 & 2.993 & -2.475 & 0.014 \\
\hline
\end{tabular}

BS, bowel Symptoms; CD, Crohn's disease; EF, emotional function; IBDQ, Inflammatory Bowel Disease Questionnaire; SF, social function; SS, systemic symptoms. 
results in a larger strain on overall healthcare during the pandemic. Therefore, maintenance of IBD care is essential.

Our multivariate analysis showed that there were no significant differences in HRQoL between patients with $\mathrm{UC}$ and patients with $\mathrm{CD}$. This is in line with the previous literature. ${ }^{38}$ Furthermore, this study showed that a history of surgery was a significant predictor for a lower HRQoL for several different physical and emotional domains of both HRQoL questionnaires. These findings are presented in previous studies as well. ${ }^{4041}$ However, due to our study design, our findings should be interpreted cautiously as other studies describe that surgical intervention can play an important role in improving HRQoL in patients with IBD on the long term. ${ }^{42}{ }^{43}$ Furthermore, this study shows that increased age and female patients with IBD scored lower on the physical aspects of the HRQoL questionnaires, which is described previously. ${ }^{445}$ This study illustrates that increased age is a significant predictor for a higher HRQoL score on the emotional function domain of the IBDQ and vitality domain and MCS of the SF-36. The vitality domain of the SF-36 makes an important contribution to the overall emotional health of patients and focuses, for examplem, on level of energy, dispiritedness and fatigue experience. ${ }^{46}$ The higher results on emotional health and vitality domains may indicate that disease-adapting and disease-coping ability is better in older patients with IBD compared with younger patients. ${ }^{478}$ This association between the contribution made by increased age on the mental HRQoL is reported earlier. ${ }^{49}$

This study has some limitations. First, our study has not included clinical follow-up data of our participants. However, because IBD treatment is partly based on symptoms of the patients, ${ }^{13} 16$ and therefore the HRQoL, this study gives a good indication of the current health status of our study population during the rapidly spread pandemic. Second, the data from the questionnaires were collected online, with potential under-representation of older patients. The average age of our study population is almost 53 years. This is in line with previous IBD studies. ${ }^{26} 5051$ Third, as the survey was conducted just after the first wave, all respondents experienced the full first wave of the COVID-19 pandemic. However, the influence of other factors on the HRQoL in patients with IBD, such as social isolation, cannot be directly determined. Finally, due to the unexpected onset of the COVID-19 pandemic and because it was the first time that we invited all patients of the Dutch Crohn's and Colitis Association to participate in filling out the IBDQ and SF-36, we were not able to provide a pre-COVID-19 control group. However, we used four Dutch IBD studies to serve as pre-COVID-19 control groups from similar background populations, to compare our data as closely as possible. More research is warranted to follow up our study population to obtain advanced information to determine their HRQoL outside the pandemic. Furthermore, additional research is required to determine the effect and predictors of postponed IBD care on clinical deterioration, thereby enabling to determine for which patients with IBD a delay of treatment is feasible and for which patients delay of IBD care could lead to increased morbidity and thereby an increased demand for healthcare resources.

In conclusion, this study shows that the HRQoL in patients with IBD during the COVID-19 pandemic is low. Furthermore, this study showed that older female patients have the lowest physical HRQoL. In the event of a next wave of the COVID-19 pandemic, caution in postponing IBD care is essential to prevent a decrease in the HRQoL of patients with IBD.

Contributors EdB contributed to the conception and design of the study, analysed and interpreted the patient data, and contributed to writing and critical revision of the article. MDF contributed to the conception and design of the study, analysed and interpreted the patient data, and contributed to writing and critical revision of the article. VM, BO, FDMvS, OWB and HHF contributed to the conception and design of the study and critical revision of the article. MRV contributed to the conception and design of the study, analysed and interpreted the patient data, and contributed to writing and critical revision of the article. MCR contributed to the conception and design of the study, analysed and interpreted the patient data, and contributed to writing and critical revision of the article. All authors read and approved the final manuscript.

Funding The authors have not declared a specific grant for this research from any funding agency in the public, commercial or not-for-profit sectors.

Competing interests None declared.

Patient consent for publication Not required.

Ethics approval The ethics committee of the UMC Utrecht approved this study and decided that patient informed consent was not required. Data were obtained through questionnaires of participants registered in the database of the Dutch Crohn's and Colitis Association.

Provenance and peer review Not commissioned; externally peer reviewed.

Data availability statement Data are available upon reasonable request.

Open access This is an open access article distributed in accordance with the Creative Commons Attribution Non Commercial (CC BY-NC 4.0) license, which permits others to distribute, remix, adapt, build upon this work non-commercially, and license their derivative works on different terms, provided the original work is properly cited, appropriate credit is given, any changes made indicated, and the use is non-commercial. See: http://creativecommons.org/licenses/by-nc/4.0/.

ORCID iD

Ellen de Bock http://orcid.org/0000-0002-5796-1617

\section{REFERENCES}

1 Al-Jabir A, Kerwan A, Nicola M, et al. Impact of the Coronavirus (COVID-19) pandemic on surgical practice - Part 1. Int J Surg 2020;79:168-79.

2 Al-Jabir A, Kerwan A, Nicola M, et al. Impact of the Coronavirus (COVID-19) pandemic on surgical practice - Part 2 (surgical prioritisation). Int J Surg 2020;79:233-48.

3 NVVH. Handle for surgical procedures during corona crisis, 2020.

4 McBride KE, Brown KGM, Fisher OM, et al. Impact of the COVID-19 pandemic on surgical services: early experiences at a nominated COVID-19 centre. ANZ J Surg 2020;90:663-5.

5 Zhang Y-F, Quu Y, He J-S, et al. Impact of COVID-19 outbreak on the care of patients with inflammatory bowel disease: a comparison before and after the outbreak in South China. J Gastroenterol Hepatol 2021;36:700-9.

6 Chen Y, Yu Q, Farraye FA, et al. Patterns of endoscopy during COVID-19 pandemic: a global survey of interventional inflammatory bowel disease practice. Intest Res 2020. doi:10.5217/ir.2020.00037. [Epub ahead of print: 0206 2020].

7 Kennedy NA, Jones G-R, Lamb CA, et al. British Society of gastroenterology guidance for management of inflammatory bowel disease during the COVID-19 pandemic. Gut 2020;69:984-90.

8 Magro F, Rahier J-F, Abreu C, et al. Inflammatory Bowel Disease Management During the COVID-19 Outbreak: The Ten Do's 
and Don'ts from the ECCO-COVID Taskforce. J Crohn's Colitis 2020;14:S798-806. doi:10.1093/ecco-jcc/jjaa160

9 Sharma E, Meade S, D'Errico F, et al. The effects of COVID-19 on IBD prescribing and service provision in a UK tertiary centre. GastroHep 2020;2:318-26.

10 Nakase H, Matsumoto T, Matsuura M, et al. Expert opinions on the current therapeutic management of inflammatory bowel disease during the COVID-19 pandemic: Japan IBD COVID-19 Taskforce, intractable diseases, the health and labor sciences research. Digestion 2020:1-9.

11 RIVM: Rijksinstituut voor Volksgezondheid en Milieu. Measures against the spread of the coronavirus, intelligent lockdown [Internet], 2020. Available: https://www.rijksoverheid.nl/onderwerpen/ coronavirus-tijdlijn/maart-2020-maatregelen-tegen-verspreidingcoronavirus

12 Molodecky NA, Soon IS, Rabi DM, et al. Increasing incidence and prevalence of the inflammatory bowel diseases with time, based on systematic review. Gastroenterology 2012;142:46-54. e42.

13 Lamb CA, Kennedy NA, Raine T, et al. British Society of gastroenterology consensus guidelines on the management of inflammatory bowel disease in adults. Gut 2019;68:s1-106.

14 Kornbluth A, Sachar DB, Practice Parameters Committee of the American College of Gastroenterology. Ulcerative colitis practice guidelines in adults: American College of gastroenterology, practice parameters Committee. Am J Gastroenterol 2010:105:501-23.

15 Hwang JM, Varma MG. Surgery for inflammatory bowel disease. World J Gastroenterol 2008;14:2678.

16 Matsuoka K, Kobayashi T, Ueno F, et al. Evidence-based clinical practice guidelines for inflammatory bowel disease. J Gastroenterol 2018;53:305-53.

17 Dutch Crohn's and Colitis association. Crohn and Colitis NL [Internet]. Available: https://www.crohn-colitis.nl

18 Ware JE, Sherbourne CD. The MOS 36-item short-form health survey (SF-36). I. conceptual framework and item selection. Med Care 1992;30:473-83

19 Ware JE. Sf-36 health survey update. Spine 2000;25:3130-9.

20 Russel MG, Pastoor CJ, Brandon S, et al. Validation of the Dutch translation of the inflammatory bowel disease questionnaire (IBDQ): a health-related quality of life questionnaire in inflammatory bowel disease. Digestion 1997;58:282-8.

21 Guyatt G, Mitchell A, Irvine EJ, et al. A new measure of health status for clinical trials in inflammatory bowel disease. Gastroenterology 1989;96:804-10.

22 Te Groen M, Derks MEW, Kuijpers CCHJ, et al. Reduction in inflammatory bowel disease healthcare during the coronavirus disease 2019 pandemic: a nationwide retrospective cohort study. Gastroenterology 2021:160:935-7.

23 Vafaei H, Roozmeh S, Hessami K, et al. Obstetrics healthcare providers' mental health and quality of life during COVID-19 pandemic: multicenter study from eight cities in Iran. Psychol Res Behav Manag 2020;13:563-71.

24 Ponsioen CY, de Groof EJ, Eshuis EJ, et al. Laparoscopic ileocaecal resection versus infliximab for terminal ileitis in Crohn's disease: a randomised controlled, open-label, multicentre trial. Lancet Gastroenterol Hepatol 2017; 2:785-92.

25 Vogelaar L, van't Spijker A, Timman R, et al. Fatigue management in patients with IBD: a randomised controlled trial. Gut 2014;63:911-8.

26 de Jong ME, Taal E, Thomas PWA, et al. Cross-cultural translation and validation of the IBD-control questionnaire in the Netherlands: a patient-reported outcome measure in inflammatory bowel disease. Scand J Gastroenterol 2021:56:155-61.

27 Danese S, Cecconi M, Spinelli A. Management of IBD during the COVID-19 outbreak: resetting clinical priorities. Nat Rev Gastroenterol Hepatol 2020;17:253-5.

28 Agrawal M, Tepler A, Hong S, et al. The impact of delay between biologic prescription and therapy initiation on clinical outcomes in inflammatory bowel disease patients. Gastroenterology 2019;157:e23.

29 Dewint $\mathrm{P}$, Hansen BE, Verhey E, et al. Adalimumab combined with ciprofloxacin is superior to adalimumab monotherapy in perianal fistula closure in Crohn's disease: a randomised, double-blind, placebo controlled trial (ADAFI). Gut 2014;63:292-9.

30 Harris RJ, Downey L, Smith TR, et al. Life in lockdown: experiences of patients with IBD during COVID-19. BMJ Open Gastroenterol 2020;7:e000541.

31 Cheema M, Mitrev N, Hall L, et al. Depression, anxiety and stress among patients with inflammatory bowel disease during the COVID-19 pandemic: Australian national survey. BMJ Open Gastroenterol 2021;8:e000581.

32 Niv G, Bar Josef S, Ben Bassat O, et al. Quality of life and uncertainty in Crohn's disease. Qual Life Res 2017;26:1609-16.

33 Colombel J-F, Panaccione R, Bossuyt P, et al. Effect of tight control management on Crohn's disease (CALM): a multicentre, randomised, controlled phase 3 trial. Lancet 2017;390:2779-89.

34 Colombel J-F, D'haens G, Lee W-J, et al. Outcomes and strategies to support a Treat-to-target approach in inflammatory bowel disease: a systematic review. J Crohns Colitis 2020:14:254-66.

35 Randall J, Singh B, Warren BF, et al. Delayed surgery for acute severe colitis is associated with increased risk of postoperative complications. Br J Surg 2010;97:404-9.

36 Lytvyak E, Sutton RT, Dieleman LA, et al. Management of inflammatory bowel disease patients with clinical care pathways reduces emergency department utilization. Crohns Colitis 360 2020;2.

37 Habibi F, Habibi ME, Gharavinia A, et al. Quality of life in inflammatory bowel disease patients: a cross-sectional study. J Res Med Sci 2017;22:104.

38 Kalafateli M, Triantos C, Theocharis G, et al. Health-related quality of life in patients with inflammatory bowel disease: a single-center experience. Ann Gastroenterol 2013;26:243-8.

39 Jäghult S, Saboonchi F, Johansson U-B, et al. Identifying predictors of low health-related quality of life among patients with inflammatory bowel disease: comparison between Crohn's disease and ulcerative colitis with disease duration. J Clin Nurs 2011:20:1578-87.

40 Cioffi I, Imperatore N, Di Vincenzo O, et al. Association between Health-Related Quality of Life and Nutritional Status in Adult Patients with Crohn's Disease. Nutrients 2020;12:746.

41 Larussa T, Flauti D, Abenavoli L, et al. The reality of patient-reported outcomes of health-related quality of life in an Italian cohort of patients with inflammatory bowel disease: results from a crosssectional study. J Clin Med 2020;9:2416.

42 Tariverdian M, Leowardi C, Hinz U, et al. Quality of life after restorative proctocolectomy for ulcerative colitis: preoperative status and long-term results. Inflamm Bowel Dis 2007:13:1228-35.

43 Ha FJ, Thong L, Khalil H. Quality of life after intestinal resection in patients with Crohn disease: a systematic review. Dig Surg 2017;34:355-63.

44 Bernklev T, Jahnsen J, Aadland E, et al. Health-related quality of life in patients with inflammatory bowel disease five years after the initial diagnosis. Scand J Gastroenterol 2004;39:365-73.

45 Sajadinejad MS, Asgari K, Molavi $\mathrm{H}$, et al. Psychological issues in inflammatory bowel disease: an overview. Gastroenterol Res Pract 2012:2012:1-11.

46 Ware JE, Kosinski MKS. Sf-36 physical and mental health summary scales: a user's manual. Boston: The Health Institute, New England Medical Center, 1994: 188

47 Jeste DV, Savla GN, Thompson WK, et al. Association between older age and more successful aging: critical role of resilience and depression. Am J Psychiatry 2013;170:188-96.

48 Gooding PA, Hurst A, Johnson J, et al. Psychological resilience in young and older adults. Int J Geriatr Psychiatry 2012;27:262-70.

49 Velonias G, Conway G, Andrews E, et al. Older age- and healthrelated quality of life in inflammatory bowel diseases. Inflamm Bowel Dis 2017;23:283-8.

50 Romberg-Camps MJL, Bol Y, Dagnelie PC, et al. Fatigue and healthrelated quality of life in inflammatory bowel disease. Inflamm Bowel Dis 2010;16:2137-47.

51 Spagnuolo R, Larussa T, lannelli C, et al. COVID-19 and inflammatory bowel disease: patient knowledge and perceptions in a single center survey. Medicina 2020;56:407. 